\title{
Corrosion Inhibition of Aluminium using 3-Hydroxy flavone in the Presence of Quarternary Ammonium Salts in $\mathrm{NaOH}$ Medium
}

\author{
J. Morris Princey and Prabavathi Nagarajan* \\ P.G. \& Research Department of Chemistry, Bishop Heber College (Autonomous), Tiruchirapalli, \\ Tamil Nadu, - 620017, India. *E-mail: drprabahod@gmail.com \\ (Received November 17, 2011; Accepted February 28, 2012)
}

\begin{abstract}
The anticorrosive effect of 3-Hydroxyflavone (3HF) in combination with quarternary ammonium bromide and iodide salts (QAB and QAI) for aluminium corrosion in $\mathrm{NaOH}$ medium was studied at the temperature range of $303 \mathrm{~K}$ $323 \mathrm{~K}$ using weight loss study, potentiodynamic polarization study and impedance spectroscopic measurements. The results revealed that the inhibition efficiency increases with the inhibitor concentration and it further increases on the addition of quarternary ammonium bromide and iodide salts. The enhanced inhibition efficiency of the inhibitor in the presence of quarternary ammonium salts may be due to synergistic effect. The adsorption process of $3 \mathrm{HF}$ on the aluminium surface obeys Langmuir's adsorption isotherm. The mechanism of adsorption is further supported by Scanning Electron Microscopic study (SEM).
\end{abstract}

Key words: 3-Hydroxyflavone (3HF), Quarternary ammonium salts, Aluminium, Electrochemical measurements, Synergism

\section{INTRODUCTION}

Aluminium is an important subject of research because of its abundance and easiness in handling. In addition aluminium is justified by low price, high electrical capacity and high energy density. ${ }^{1}$ In order to control aluminuim corrosion, the main strategy is to effectively isolate the metal from the corrosive agents by the use of corrosion inhibitors. Inorganic substances like phosphates, chromates, dichromates and arsenates have been found to be effective corrosion inhibitors but they are toxic in nature. Organic compounds having high electron density at the hetero atoms have the corrosion inhibition efficiency due to the functional groups ${ }^{2-6}$ present in aromatic and heterocyclic rings along with electron-rich elements like nitrogen, sulfur and oxygen. Corrosion inhibition occurs via adsorption of the compounds on the corroding metal surface and the efficiency of the inhibition depends on the mechanical structural and chemical characteristics ${ }^{7}$ of the adsorbed layers. As a contribution to the current interest on eco- friendly corrosion inhibitors, the present study is focused on the inhibiting efficiency of 3HF on aluminium in $\mathrm{NaOH}$ medium. Reports on the effects of quarternary ammonium salts in combination with green inhibitors for corrosion inhibition of metals is very scanty. ${ }^{8-10}$ Therefore the synergistic effect of the additives namely QAB and QAI has also been studied.

\section{EXPERIMENTAL}

\section{Reagents}

The commercial aluminium specimen with chemical composition (wt.\%): $\mathrm{Al}(99.594 \%), \mathrm{Cu}(0.002 \%), \mathrm{Zn}(0.003 \%)$, $\mathrm{Pb}(0.100 \%), \mathrm{Co}(0.050 \%), \mathrm{Ni}(0.011 \%), \mathrm{Fe}(0.179 \%)$ and $\mathrm{Cr}(0.082 \%)$ was used for the study. The flavonoid compound 3HF (Fig. 1) was purchased from Research Organics, Chennai, and re-crystallized from methanol. All chemicals used were of Analytical Grade.

\section{Recommended Procedure}

The aluminum specimens were abraded with emery paper of different grades before each experiment and washed with de-ionized water and degreased with acetone and dried with a stream of air.

\section{Weight Loss Study}

The aluminium coupons with dimension $3.0 \times 1.0 \times 0.2$ $\mathrm{cm}^{3}$ were used for weight loss studies. The coupons were weighed and the surface areas of all specimens were calculated before and after immersing them in $100 \mathrm{ml}$ test solutions of $\mathrm{NaOH}$ with different concentrations for a time period of 2 hours. The weight loss studies were carried out at $303 \mathrm{~K}, 313 \mathrm{~K}$ and $323 \mathrm{~K}$.

The inhibition efficiency was calculated from the corrosion rate ${ }^{11}$ using the following equation. 


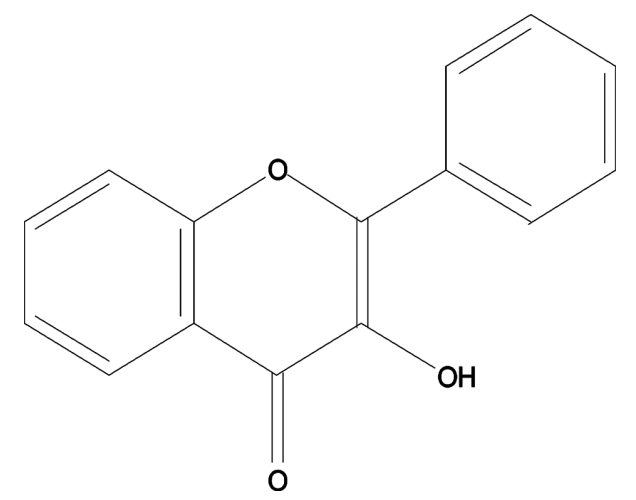

Fig. 1. 3-Hydroxyflavone (3HF).

$$
I E(\%)=\frac{C R_{\text {blank }}-C R_{\text {inh }}}{C R_{\text {blank }}} \times 100
$$

where $C R_{\text {blank }}$ and $C R_{\text {inh }}$. are the corrosion rates in the absence and presence of the inhibitor.

\section{Electrochemical Measurements}

The electrochemical measurements were carried out using a PRINCETON versa STAT Potentiostat-Galvanostat research instrument and a conventional three electrode cell set up. Aluminium was used as the working electrode with an exposed area of $1 \mathrm{~cm}^{2}$, saturated calomel as the reference electrode and platinum as the auxiliary electrode. All electrochemical measurements were carried out for the inhibited and uninhibited solutions. The Electrochemical impedance spectroscopy (EIS) measurements were performed at an open circuit potential after 15 minutes of immersion in the test solution with the amplitude of $10 \mathrm{mV}$. The covered frequency range was $30,000 \mathrm{~Hz}$ to $1 \mathrm{~Hz}$. The impedance diagrams are given as Nyquist plots. Fig. 2 represents the electrical equivalent circuit for the ac impedance measurement. The charge transfer values $\left(R_{c t}\right)$ were calculated from the difference in the high frequency values. The capacitance of the double layer $\left(\mathrm{C}_{\mathrm{dl}}\right)$ was estimated from the frequency $(f)$ at which the imaginary

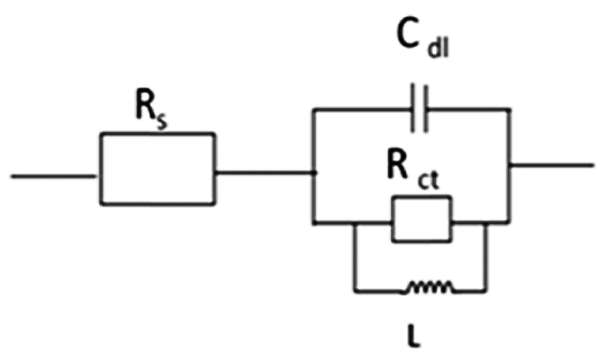

Fig. 2. The equivalent circuit model used to fit the ac impedance measurement. component of the impedance ( $\left.Z^{\prime \prime}\right)$ is maximum and obtained using the following equation

$$
f\left(-Z^{\prime \prime}\right)=\frac{1}{2 \pi C_{d l} R_{c t}}
$$

The potentiodynamic polarization (PDP) measurements were carried out at a sweep range from $-1.7 \mathrm{~V}$ to $-1.3 \mathrm{~V}$. By the Tafel extrapolation method, electrochemical parameters like corrosion current density $\left(\mathrm{I}_{\text {corr }}\right)$ and corrosion potential $\left(\mathrm{E}_{\text {corr }}\right)$. The percentage inhibition efficiency can be obtained from the electrochemical measurements using the following formulae

$$
P D P: I E(\%)=\frac{I_{\text {corr }}-I_{\text {corr }}^{\prime}}{I_{\text {corr }}} \times 100
$$

where $I_{\text {corr }}$ and $I_{\text {corr }}$ are the corrosion current densities without and with the inhibitor.

$$
E I S: I E(\%)=\frac{R_{c t}^{\prime}-R_{c t}}{R_{c t}^{\prime}} \times 100
$$

where $\mathrm{R}_{\mathrm{ct}}$ and $\mathrm{R}_{\mathrm{ct}}^{\prime}$ are the charge transfer resistance values in the absence and presence of the inhibitor respectively.

\section{SEM Analysis}

The aluminium specimens were immersed in $1 \mathrm{M} \mathrm{NaOH}$ with an optimum concentration of the inhibitor and without the inhibitor for 2 hours. Then, they were removed, rinsed quickly with acetone and dried. The surface morphology was studied using a Hitachi Model S-3000H (Resolution- $3.5 \mathrm{~nm}$ ) scanning electron microscope.

\section{RESULTS AND DISCUSSION}

\section{Weight Loss Study}

The values of percentage inhibition efficiency (IE\%) obtained for different concentrations of the inhibitor at different temperatures are given in Table 1. From the data

Table 1. Effect of temperature on the inhibition efficiency of 3HF alone and in the presence of quarternary ammonium salts on aluminium in $1 \mathrm{M} \mathrm{NaOH}$ by weight loss method

\begin{tabular}{cccc}
\hline Concentration of & \multicolumn{3}{c}{ IE $(\%)$} \\
\cline { 2 - 4 } inhibitor $\times 10^{-5} \mathrm{M}$ & $303 \mathrm{~K}$ & $313 \mathrm{~K}$ & $323 \mathrm{~K}$ \\
\hline Blank & - & - & - \\
1 & 29.57 & 27.15 & 23.81 \\
2 & 38.51 & 35.18 & 34.17 \\
3 & 47.50 & 44.10 & 41.83 \\
4 & 56.51 & 50.42 & 46.33 \\
3HF+QAB & 68.17 & 60.05 & 54.18 \\
3HF+QAI & 85.98 & 79.19 & 71.85 \\
\hline
\end{tabular}


Table 2. Thermodynamic parameters for the inhibition of corrosion of aluminium in $1 \mathrm{M} \mathrm{NaOH}$ by $3 \mathrm{HF}$

\begin{tabular}{cccc}
\hline $\begin{array}{c}\text { Concentration of } \\
\text { inhibitor } \times 10^{-5} \mathrm{M}\end{array}$ & $\begin{array}{c}E_{a} \\
\mathrm{kJmol}^{-1}\end{array}$ & $\begin{array}{c}-\Delta H_{a d s}^{o} \\
\mathrm{kJmol}^{-1}\end{array}$ & $\begin{array}{c}-\Delta G_{a d s}^{o} \\
\mathrm{kJmol}^{-1}\end{array}$ \\
\hline Blank & 32.82 & 27.45 & - \\
1 & 35.53 & 29.63 & 36.93 \\
2 & 36.96 & 31.11 & 31.31 \\
3 & 37.74 & 31.42 & 36.10 \\
4 & 44.46 & 37.70 & 36.28 \\
\hline
\end{tabular}

it can be seen that the inhibition efficiency increases as the concentration of the inhibitor increases due to the adsorption of the inhibitor ${ }^{12}$ on the metal surface. It is also seen that the inhibition efficiency of the inhibitor decreases with increase in temperature ${ }^{13}$ suggesting physisorption. This may be due to the desorption of the inhibitor molecules ${ }^{14}$ from the metal surface at higher temperatures.

The thermodynamic parameters were also calculated (Table 2) From the IE (\%) values, activation energy ( $\left.\mathrm{E}_{\mathrm{a}}\right)$ was calculated using Arrhenius equation. The free energy of adsorption $\left(\Delta G_{a d s}^{\circ}\right)$ at different temperatures was calculated using the following equation ${ }^{15}$

$$
\Delta G_{a d s}^{\circ}=-R T \ln \left(55.5 \mathrm{~K}_{\mathrm{ads}}\right)
$$

where $R$ is the molar gas constant, $T$ is the absolute temperature and 55.5 is the molar concentration of moles of water in $\mathrm{mol} / \mathrm{dm}^{-3} . K_{a d s}$ is given by the following expression

$$
K_{a d s}=\left(\frac{\theta}{1-\theta}\right) \times \frac{1}{C}
$$

where $\theta$ is the degree of surface coverage (Table 3 ) and $\mathrm{C}$ is the concentration of the inhibitor. The enthalpy of activation, $\Delta H^{o}$ ads. is another criterion from which the mode of adsorption can be probed. $\Delta H^{o}$ ads. was obtained by applying the transition state equation.

Table 3. Effect of $3 \mathrm{HF}$ alone and along with of quarternary ammonium salts on rate of corrosion and surface coverage for aluminium in $1 \mathrm{M} \mathrm{NaOH}$ at $303 \mathrm{~K}$

\begin{tabular}{cccc}
\hline $\begin{array}{c}\text { Concentration of } \\
\text { inhibitor } \times 10^{-5} \mathrm{M}\end{array}$ & $\begin{array}{c}\text { Rate of corrosion } \\
\mathrm{g} / \mathrm{cm}^{2} / \mathrm{min}\end{array}$ & $\mathrm{IE}(\%)$ & $\begin{array}{c}\text { Surface } \\
\text { Coverage }(\theta)\end{array}$ \\
\hline Blank & 12.63 & - & - \\
1 & 8.89 & 29.57 & 0.2957 \\
2 & 7.76 & 38.51 & 0.3851 \\
3 & 6.63 & 47.50 & 0.4750 \\
4 & 5.40 & 56.51 & 0.5651 \\
3HF+QAB & 4.02 & 68.17 & 0.6817 \\
3HF+QAI & 1.77 & 85.98 & 0.8598 \\
\hline
\end{tabular}

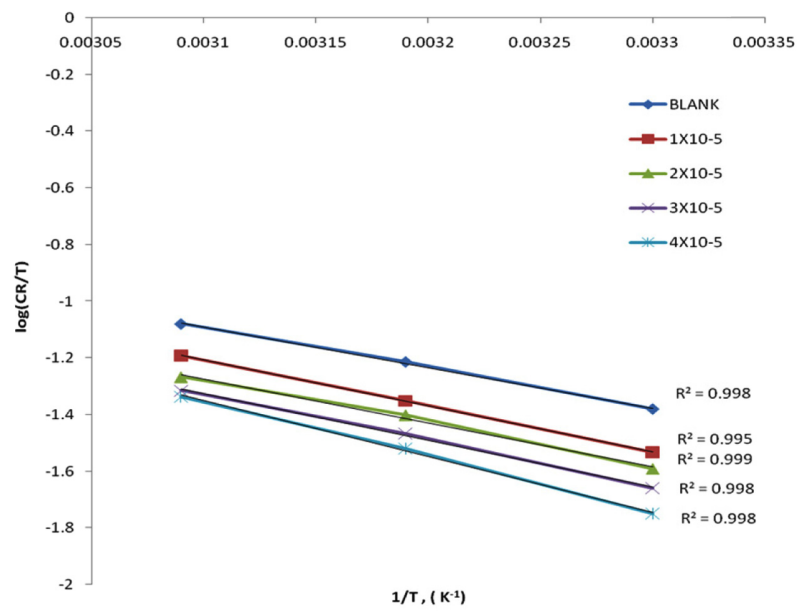

Fig. 3. Thermodynamic plot for HPC at 303, 313 and 323 $\pm 1 \mathrm{~K}$.

$$
C R=\frac{R T}{N h} \exp \left[\frac{\Delta S_{a d s}^{o}}{R}\right] \exp \left[\frac{-\Delta H_{a d s}^{o}}{R T}\right]
$$

where $C R$ is the corrosion rate, $h$ the Planck's constant, $N$ the Avogadro's number, $\Delta S^{o}$ the entropy of activation, $T$ the absolute temperature and $R$ the universal gas constant. A plot of $\log (C R / T)$ against $1 / T$ (Fig. 3) was made for the blank and different concentrations of the inhibitor. From the slope value, $\Delta H_{a d s}^{o}$ values were computed.

The negative values of $\Delta G^{o}$ ads. suggest that the adsorption of the inhibitor on to the aluminum surface is a spontaneous process and the adsorbed layer is stable. ${ }^{16}$ The presence of the inhibitor increases the value of the activation energy $\left(E_{a}\right)$ indicating physical adsorption ${ }^{17-19}$ of the inhibitor on the metal surface. The enthalpy changes $\left(\Delta H_{\text {ads. }}^{o}\right.$ ) are negative indicating the exothermic ${ }^{20}$ nature of the adsorption process.

\section{Potentiodynamic Polarization (PDP) Measurements}

The anodic and cathodic polarization curves for aluminium in $1 \mathrm{M} \mathrm{NaOH}$ solution with and without the inhibitor are shown in Fig. 4. and 5. It is clear that both cathodic (hydrogen evolution) and anodic (metal dissolution) reactions of aluminium were inhibited with the increasing concentration of the inhibitor. The result suggests that it is a mixed type of inhibitor. The values of the polarization parameters ( $\mathrm{I}_{\text {corr. }}, \mathrm{E}_{\text {corr. }}$ and $\mathrm{IE} \%$ ) are listed in Table 4. As the inhibitor concentration increases, the $\mathrm{I}_{\text {corr. }}$. value decreases thereby increasing the inhibition efficiency. 


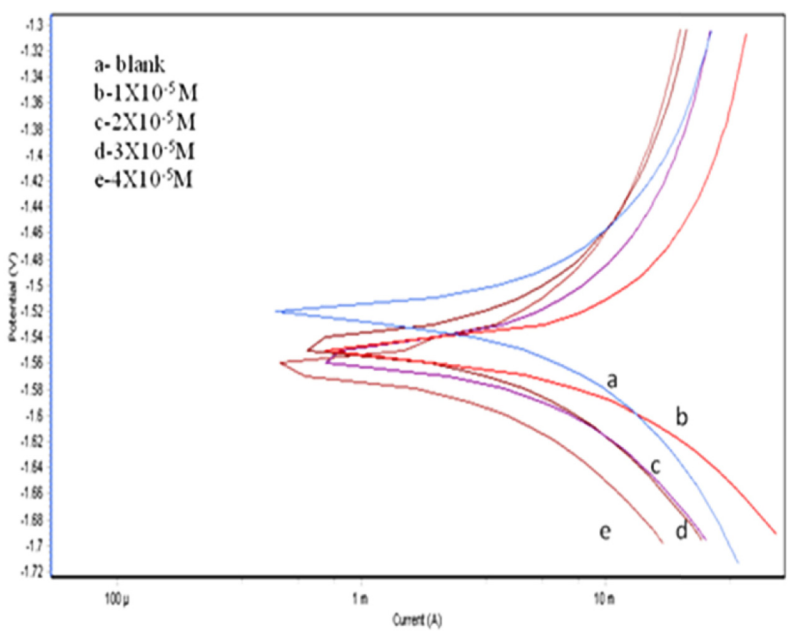

Fig. 4. Potentiodynamic polarization curves for aluminium in $1 \mathrm{M} \mathrm{NaOH}$ with and without the inhibitor at different concentrations.

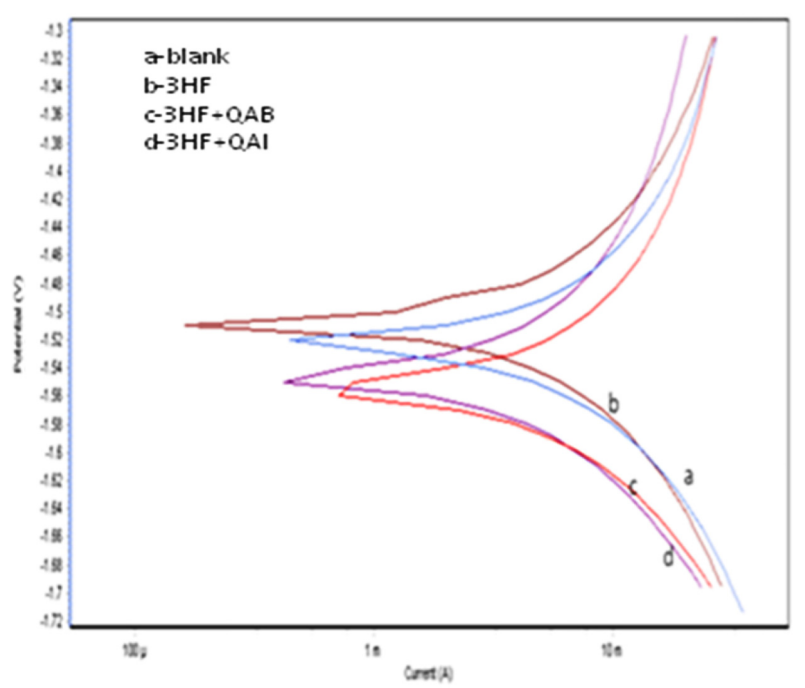

Fig. 5. Potentiodynamic polarization curves for aluminium in $1 \mathrm{M} \mathrm{NaOH}$ with the quarternary ammonium salts.

Table 4. Potentiodynamic polarization parameters for aluminum in $1 \mathrm{M} \mathrm{NaOH}$ with and without the inhibitor at different concentrations

\begin{tabular}{cccc}
\hline $\begin{array}{c}\text { Concentration of } \\
\text { inhibitor } \times 10^{-5} \mathrm{M}\end{array}$ & $\begin{array}{c}\mathrm{I}_{\text {corr. }} \\
\mu \mathrm{A} / \mathrm{cm}^{2}\end{array}$ & $\begin{array}{c}-\mathrm{E}_{\text {corr. }} \\
(\mathrm{mV})\end{array}$ & $\mathrm{IE}(\%)$ \\
\hline Blank & 77,837 & $1,522.9$ & - \\
1 & 58,714 & $1,564.9$ & 24 \\
2 & 55,256 & $1,555.3$ & 29 \\
3 & 45,124 & $1,564.1$ & 41 \\
4 & 40,933 & $1,545.4$ & 47 \\
3HF+QAB & 36,906 & $1,546.4$ & 52 \\
3HF+QAI & 15,835 & $1,376.1$ & 79 \\
\hline
\end{tabular}

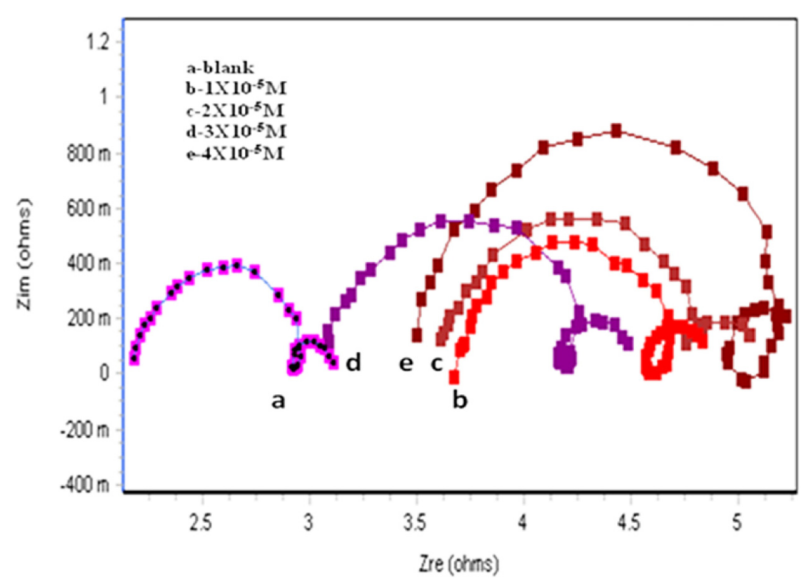

Fig. 6. Nyquist plots of aluminium in $1 \mathrm{M} \mathrm{NaOH}$ with and without the inhibitor at different concentrations.

Table 5. Corrosion parameters obtained from EIS measurements for aluminium in $1 \mathrm{M} \mathrm{NaOH}$ with and without the inhibitor at different concentrations

\begin{tabular}{cccc}
\hline $\begin{array}{c}\text { Concentration of } \\
\text { inhibitor } \times 10^{-5} \mathrm{M}\end{array}$ & $\begin{array}{c}\mathrm{R}_{\mathrm{ct}} \\
\Omega \mathrm{cm}^{2}\end{array}$ & $\begin{array}{c}\mathrm{C}_{\mathrm{dl}} \\
\mu \mathrm{F} / \mathrm{cm}^{2}\end{array}$ & $\mathrm{IE}(\%)$ \\
\hline Blank & 0.774 & 210.49 & - \\
1 & 1.000 & 1332.9 & 22 \\
2 & 1.121 & 1192.7 & 30 \\
3 & 1.214 & 1099.1 & 36 \\
4 & 1.630 & 820.4 & 52 \\
3HF+QAB & 1.841 & 72.48 & 58 \\
3HF+QAI & 2.170 & 61.60 & 64 \\
\hline
\end{tabular}

\section{Electrochemical Impedance Spectroscopy (EIS) Mea- surements}

The EIS of aluminium in $1 \mathrm{M} \mathrm{NaOH}$ is summarized as Nyquist plots in Fig. 6. The plots clearly show that the addition of increasing amounts of the inhibitor causes an increase in electrochemical impedance. ${ }^{20}$ The Nyquist plots show three parts: the capacitive loop in the high frequency region, the inductive loop in the middle frequency region and the capacitive loop in low frequency region. The values of $\mathrm{R}_{\mathrm{ct}}, \mathrm{C}_{\mathrm{dl}}$ and IE(\%) are given in Table 5 . The complete inspection of the values shows that $R_{c t}$ values increases while $C_{d l}$ values decreases with increase in the inhibitor concentration. This may be due to the increased surface coverage which led to an increase in $\operatorname{IE}(\%)$.

\section{Adsorption Behavior}

To ascertain the nature of adsorption of 3HF on aluminium in $1 \mathrm{M} \mathrm{NaOH}$ attempts were made to fit various isotherms such as Freundlich, Temkin, Langmuir and Frumkin. However the best fit was obtained (Fig. 7) only with Langmuir adsorption which supports the monolayer 


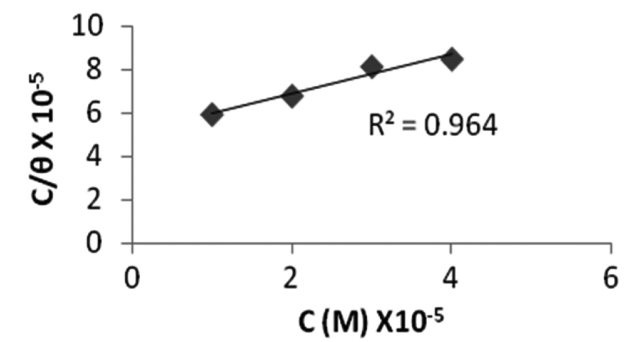

Fig. 7. Langmuir adsorption isotherm for $3 \mathrm{HF}$.

Table 6. Synergistic effect of QAB and QAI on the inhibition efficiency of $3 \mathrm{HF}$ (from weight loss studies)

\begin{tabular}{ccc}
\hline Inhibitor & $\begin{array}{c}\text { Inhibition Efficiency } \\
(\%)\end{array}$ & $\begin{array}{c}\text { Synergism } \\
\text { Parameter, } S_{\theta}\end{array}$ \\
\hline 3HF & 38.51 & \\
QAB & 38.0 & 1.19 \\
3HF+QAB & 68.17 & \\
3HF & 38.51 & \\
QAI & 42.0 & 4.5 \\
3HF+QA1 & 85.98 & \\
\hline
\end{tabular}

adsorption of the inhibitor on the aluminium surface.

\section{Synergistic Effect}

The inhibition efficiency of the inhibitor was found to be enhanced with the addition of n-tetrabutylammonium bromide and n-tetrabutylammonium iodide along with 3 HF. Similar observations has been reported ${ }^{22}$ earlier and the enhancement of the inhibition efficiency was ascribed to the synergistic effect. The inhibition efficiency of the inhibitor increases with the addition of the quarternary ammonium salts at all temperatures studied. This can be attributed to the stabilization of adsorbed quarternary salts by electrostatic interaction with the inhibitor. This leads to greater surface coverage and higher inhibition efficiency. The synergistic effect of $\mathrm{I}^{-}$is found to be greater than $\mathrm{Br}^{-}$suggesting a possible role by ionic radii in the adsorption process. Synergism can be assessed in terms of the synergism parameter $\left(S_{\theta}\right)$ according to the following relationship ${ }^{23}$

$$
S_{\theta}=\frac{1-\theta_{1+2}}{1-\theta_{1+2}}
$$

where $\theta_{1+2}=\left(\theta_{1}+\theta_{2}\right)-\left(\theta_{1} \theta_{2}\right), \theta_{1}$ is the surface coverage by flavonoid compounds, $\theta_{2}$ the surface coverage of the additive and $\theta_{1+2}^{\prime}$ is the measured surface coverage for flavonoids in combination with additives.

\section{SEM Analysis}

The SEM images of aluminum were recorded (Figs. 8

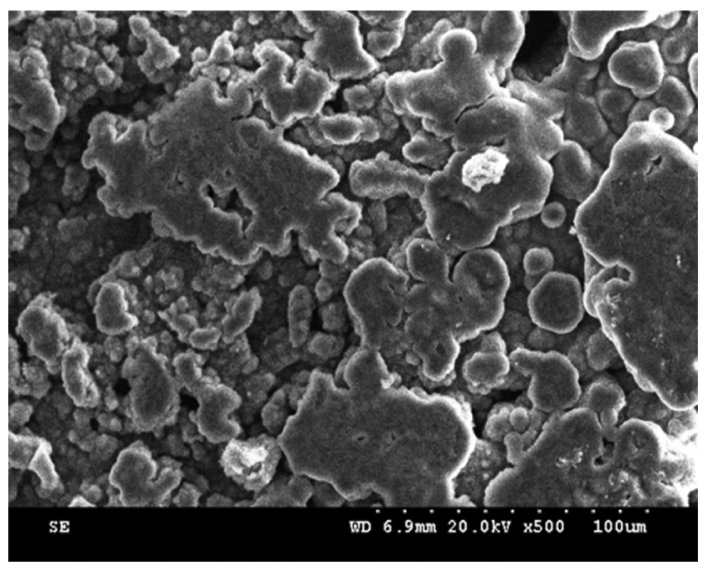

Fig. 8. SEM image of $\mathrm{Al}$ specimen kept in $1 \mathrm{M} \mathrm{NaOH}$ for 2 hours at $303 \mathrm{~K}$.

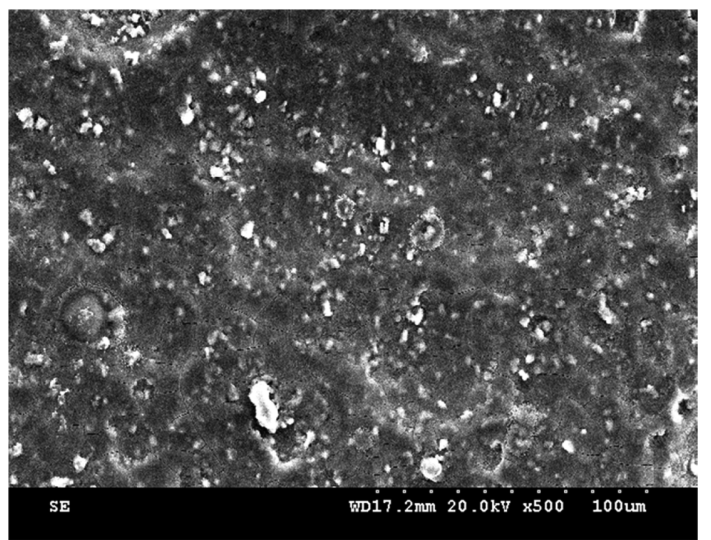

Fig. 9. SEM image of $\mathrm{Al}$ specimen kept in $1 \mathrm{M} \mathrm{NaOH}$ along with $3 \mathrm{HF}$ for 2 hours at $303 \mathrm{~K}$.

and 9) after immersion in $1 \mathrm{M} \mathrm{NaOH}$ with and without the inhibitor for a time period of 2 hours to establish the interaction of the organic molecules with the metal surface. The images of SEM confirm the changes in the surface morphology. In the absence of the inhibitor, extensive corrosion is suffered by the metal surface which is evident by the presence of hemispherical deep pits and corrosion products (Fig. 8) which is due to the attack of the alkali on the surface. The specimen immersed in the alkali along with the inhibitor has a less corroded surface. This indicates that the inhibitor molecules hinder the dissolution of aluminium by forming an organic protective film on the metal surface and thereby reducing the rate of corrosion.

\section{CONCLUSION}

The flavonoid compound $3 \mathrm{HF}$ was found to be an effective inhibitor for the corrosion of aluminium in alkaline medium. Electrochemical measurements revealed that $3 \mathrm{HF}$ 
acts as a mixed type of inhibitor. The adsorption of the inhibitor molecules was found to follow Langmuir adsorption isotherm. The data obtained from weight loss studies, potentiodynamic polarization and electrochemical impedance spectroscopic measurements were found to be in good agreement. The inhibition efficiency of $3 \mathrm{HF}$ is temperature dependant and the increase in temperature leads to decrease in the inhibition efficiency of the inhibitor. Synergism studies show that the inhibition efficiency of the flavonoid compound increases with the addition of quarternary ammonium bromide and iodide salts. The SEM analysis also provided a supporting evidence for the adsorption of the inhibitor on the metal surface.

Acknowledgement. The authors would like to thank the Principal and Management of Bishop Heber College (Autonomous), Tiruchirapalli -620 017 for the encouragement and the UGC (New Delhi) for financial support.

\section{REFERENCES}

1. Elewady, G. Y.; El-Said, I. A.; Fouda, A. Int. J. Electrochem. Sci. 2008, 3, 644.

2. Pourbiax, M. Atlas of electrochemical equilibra in aqueous solution; NACE Cebelcor: Houston, 1974; p 10.

3. Nisancioglu, K. Corrosion of aluminium alloys, Proceedings of ICAA3, 1992, 239.

4. Gomma, G. K. Mater. Chem. Phys. 1998, 55, 243.

5. Umoren, S. A.; Ogbobe, I.; Ebenso, E. E.; Ekpe, U. J. Pig- ment \& Resin Tech. 2006, 35(5), 284.

6. Oguzie, E. E. Mater. Chem. Phys. 2006, 99(2-3), 441.

7. Oguzie, E. E. Corros. Sci. 2007, 49, 1527.

8. Oguzie, E. E. Mater. Lett. 2005, 59, 1076.

9. Oguzie, E. E. Pigment \& Resin Tech. 2006, 35(6), 334.

10. Oguzie, E. E. Pigment \& Resin Tech. 2005, 34(6), 321.

11. Ebenso, E. E. Alemu, H.; Umoren, A.; Obot, I. B. Int. J. Electrochem. Sci. 2008, 3, 1325.

12. Obot, I. B. Int. J. Electrochem. Sci. 2009, 4, 1277.

13. Elewady, G. Y.; El-Said, I. A.; Fouda, A. S. Int. J. Electrochem. Sci. 2008, 3, 644.

14. Oguzie, E. Portugaliae Electrchimica Acta 2008, 26, 303.

15. Qurashi, M. A.; Ishatiaque Ahamad; Ashish Kumar Singh; Sudhish Shukala Lal Vakil Singh, B. Mater. Chem. Phys. 2008, 112, 1035.

16. Chauhan, L. R.; Gunasekaran, G. Corros. Sci. 2007, 49, 1143.

17. Umoren, S. A.; Obot, I. B.; Ebenso, E. E. E-J. Chem. 2008, 5, 355 .

18. Umoren, S. A.; Obot, I. B.; Akpabio, L. E. Pigment \& Resin Tech. 2008, 37, 98.

19. Umoren, I. B.; Obot, E. E.; Ebenso, P. C.; Okafor, O.; Ogbobe; E. E. Anti-Corros. Methods and Mater. 2006, 53(5), 752.

20. Desai, P. S.; Vashi, R. T. Indian Journal of Chemical Tech. 2010, 17, 50.

21. Ehteram Noor, A. J. Appl. Electrochem. 2009, 39, 1465.

22. Oguzie, E. E.; Onuchukwu, A. I.; Okafor, P. C.; Ebenso, E. E. Pigment \& Resin Tech. 2006, 35(2), 63.

23. Larabi, L.; Harek, Y.; Traisnel, M.; Mansri, A. J. Appl. Electrochem. 2004, 34, 833. 